\title{
The Internet as an alternative distribution and communication channel for SMEs producing quality agro-food products
}


RESUMEN

Clasificación JEL:

M37

Palabras clave:

website, apelación

al origen, empresas

agroalimentarias,

SMES

\section{ABSTRACT}

JEL Classification:

M37

Key words:

website,

Appellation of origin, agro-food firms,

SMES.
Este trabajo analiza el uso de Internet como canal de comunicación y distribución entre SEMs en el sector agroalimentario. La investigación se centra en la incorporación de este canal de marketing por empresas de una región española, que comercializa productos bajo el distintivo de calidad, estimulados por la ventaja competitiva que este medio proporciona. Con este objetivo, se investigaron 259 empresas, utilizando 62 variables descriptivas para evaluar sus websites.

This work analyses the use of the Internet as a communication and distribution channel among SMEs in the agro-food sector. The work focuses on the incorporation of this marketing channel by firms from a Spanish region commercializing products under a quality sign, encouraged by the competitive advantage this medium provides. With this objective, 259 firms are investigated, using 62 descriptive items to evaluate their websites. 


\section{Introduction}

The current work investigates small and medium-sized enterprises (SMEs) from the agro-food sector specialised in making products with the quality sign Protected Appellation of Origin (PAO) or Protected Geographical Indication (PGI). These marks or certificates are increasingly important at present. A total of 227 PAOs and PGIs exist in Spain, and they cover very diverse product categories.

PAOs and PGIs are marks of identity that consumers value extremely highly, and they are allowing SMEs from a particular region to improve the commercialisation of their products. But the progress that these firms have made fundamentally centres on the product rather than on commercialisation strategies or policies.

Thus, and with the aim of providing specific marketing solutions to favour the commercialisation of these agro-food products, the object of this study is to analyse the distribution and communication practices of the SMEs from this sector. The work focuses specifically on the Internet channel as a potential medium for commercialising these products.

In this respect, e-marketing has developed significantly in recent years. The Internet is now an extremely important communication and distribution channel, particularly for SMEs because of the efficiency-cost relation (Aguiló, 1996; Quelch and Klein, 1996 and 1996b; Bonsón and Sierra, 1997). The World Trade Organisation has called the Internet a "great leveller", as it provides a more level playing field for SMEs and large firms. SMEs can use the functions of this new channel to carry out commercial strategies that were once limited to large firms. Thus, such firms can not only make sales, but also carry out promotion techniques and public rela- tions, disseminate commercial information, conduct customer service, gather information for commercial research, and so on.

Marketing techniques using the Internet as a communication medium include advertising on the websites of firms and/or regulatory boards, e-commerce, public relations via e-mail, publicity (offering information to other host pages), sponsorship, as well as the use of discussion forums, news servers and discussion groups (Carpintier, 1996; Sánchez et al., 1997). On the other hand, the demand for products through this channel has increased markedly in recent years. Finally, this medium allows firms to exchange company information with other internal (Intranet) and external agents (suppliers, customers, etc.) much more flexibly and economically (Gómez-Limón, 2002).

All this reinforces the need to analyse the current situation of Internet use among agrofood SMEs, and the potential contribution of this communication and distribution channel to the development and growth of this sector. Thus, the electronic sale of quality agro-food products offers potential benefits, which firms have yet to fully exploit, in terms of convenience and immediacy that makes it a valuable complement to the physical store. On the other hand, the presence of these products in virtual stores provides an extra benefit apart from the sales, in terms of advertising: being present in a website that sells "quality products".

This work specifically analyses how, and how much, agro-food firms from Castile and Leon (a region in the north west of Spain) use the Internet as a communication and distribution channel for their products, as well as their positioning in this regard. The work investigates the possession of websites in 259 firms. For those 
firms that use this channel to contact the consumer, the authors analyse how developed the website is on the basis of a list of 56 items concerning: technical aspects such as usability, availability of navigation menu, presentation, or the functionalities of the website; the commercial information offered on the company, the production process (considering the preparation process, the120 technology, the preparation area and the raw materials) and the product (including the PAO/PGI under which it is commercialised); the website's adequacy as a sales medium; and other descriptive attributes of the site.

\section{Evaluation of website development by SMEs in agro-food sector}

Several authors have pointed out the extraordinary opportunities the Internet offers SMEs (Geiger and Martin, 1999; Lee, 2001; Daniel et al., 2002; Siu, 2002). In this respect, in recent years companies, including SMEs, have made a great deal of effort and progress in the use of the Internet (Stevenson and Hamill, 2002). However, progress has not been uniform in all sectors (Kula and Tatoglu, 2003): agro-food firms make less use of the potential of the Internet than firms from other sectors.

Some statistics show how a third of small companies have not yet included new technologies in their business strategies (Pratt, 2002; Auger et al., 2003). On the other hand, the design of SMEs' websites - one of the most popular Internet resources - is not entirely appropriate, either in content or in functionality, interactivity or value offered (Stevenson and Hamill, 2002).

This places limits on the extent to which this major means of interacting with consumers can be exploited. Thus, one of the basic pillars of Customer Relationship Management (CRM) is customer interactivity, which is achieved by including in the website information and services of use to the consumers (Sparkes and Thomas, 2004). On the other hand, the Internet's potential for SMEs is not limited solely to increasing customer loyalty; the medium is also a key factor in obtaining access to niche markets (Kleindl, 2000).

In the same line, Ditto and Pille (1998) classify the impact of the website on the consumers at three levels: informative, at the most basic level, using the website as a unidirectional medium to offer the same information as the traditional channels provide; transactional, making communication with the customers possible, allowing them to contact the company by e-mail, telephone or other means; and relational, acting as a key marketing tool to achieve interaction with the customers, developing a lasting relation with them. In turn, Hamill (1997) proposes a model for SMEs, offering three Internet applications in international marketing: network communications, market intelligence and global sales promotion.

In the case of Spain, according to a survey on the use of Information and Communication Technology (ICT) and e-commerce by companies in 2005-2006, conducted by INE, the Spanish National Statistics Institute, the main reasons companies in the agro-food sector give for selling over the Internet are, firstly, to keep up with competitors, to accelerate the business process, improve service quality, improve the corporate image and reduce business costs. A lower, but also significant percentage, mentions geographic expansion of the market, attracting new customers and offering a tailored service as reasons. A final, less important reason is to launch new products/services. 


\section{Table 1 - List of items used for website evaluation}

\section{Items}

\section{Information on company}

1. Company name

2. Legal form of company

3. Address and location of winery/factory

4. Indication of PAO/PGI held by company

5. Company shows its logo on website

6. Indication of product sold

7. Company shows main brands it sells

8. Information on production sold

\section{Website}

9. Development of website

10. Presence of graphics

11. Presence of images

12. Presence of mobile elements (banners...)

13. Links

14. Novelty or originality

15. Information in English or other languages

16. Usability

17. Site Map

18. Search Engine

19. Glossary

20. Date of last update

\section{Information on production}

21. Identification of product type most commercialised by company

22. Information on raw material

23. Information on preparation process

24. Information on preparation area

25. Information on technology used

26. Information on composition of products

27. Information on quality control systems

28. Recommendations on how to consume product, recipes ...

29. Weather information on location for technical purposes

30. Description of land orography for technical purposes

\section{Product}

31. Information on product portfolio or presence of catalogue

32. Displays photographs of product

33. Displays product by label

\section{Sale}

34. Shows products with prices

35. Availability of electronic sale

36. Types of payment allowed

37. Safe payment assured

38. Company has physical point of sale

39. Referral to physical establishments for sale of products

(own shops or distributors)

40. Provides information about purchase by telephone or e-mail

41. Delivery terms and other services on website are defined

42. Provides on-line sales, providing price of products marked

43. Purchase suggestions linked to price

44. Provides discounts and offers

\section{Communication}

45. Introduces company and history

46. Provides direct contact with company by post

47. Provides direct contact with company by e-mail

48. Provides direct contact with company by telephone

49. Information on exports

50. Organises site visits to company

51. Organises tasting sessions

52. Provides gastronomy-related information

53. Provides tourism-related information

54. Provides advice on health-related aspects of consumption

55. Provides sundry news on world of wine/cheese ...

56. Provides possibility of joining club or forums

57. Organizes competitions

58. Provides catalogues

59. Press dossier

60. Publishes the annual accounts

61. Opinion of endorsers

62. Shows awards and mentions 
The main problems of companies in this sector that sell over the Internet are that the product is not suited to sell online (this being the main reason mentioned by companies for not selling online), and that customers and other companies are not ready for e-commerce. Other obstacles are uncertainty about the legal framework of online sales, and security-related issues concerning payment. Logistics issues are the last problem mentioned. Apart from these issues and obstacles, companies not commercializing their products over the Internet consider that they do not need to.

\section{Methodology}

This study analyses 259 companies in the agrofood sector that make quality products from Castile and Leon. These companies were first asked if they had a website. If they did, the research team analysed the website according to a list of items developed specifically for that purpose (see Table 1).

\section{Results and discussion}

Of the 259 companies consulted, 87 have active websites, 10 have websites in construction, and 162 have no website. The rest of the work examines these 87 active websites.

\section{Development of website}

In global terms, website development obtains a positive assessment, this being considered very good in $21.84 \%$ of the websites analysed, good in $42.53 \%$, and intermediate in $33.33 \%$. Likewise, usability and appraisal of the site map both score between 7 and 10 in 88.34\% of the websites. A point clearly requiring improvement, however, is the originality of these websites. Although this is not exactly a weak point, firms should take the initiative and improve originali- ty to attract the attention of potential consumers, increasing the power of attraction and persuasion of their websites. This is also a means of contact with the consumer, conveying image.

Only one website does not show images, but very few use graphics. Mobile elements appear in $59.77 \%$ of the websites. Few websites include links to other websites. Sites can agree to include links to each other, so clearly this option is underexploited. Another aspect requiring major attention is foreign language versions of website information, an option available on just 60.92 per cent of the websites. On the other hand, only $10.34 \%$ of the websites consulted provide a search engine, and none offer a glossary. Only three of them include the date of the last update (see Table 2).

\section{Information on company}

All the websites consulted display the company name prominently, and all but three show the address of the winery or factory where the products are made. An important fact is that the company logo is displayed, as a sign that identifies it. This is the symbol that allows the consumer to recognise the company when deciding what to buy. Fully $97.70 \%$ of the websites show the logo, as well as the product sold, which is very important to aid the memory, as well as to form an association between the company and product.

In this analysis, the weakest point observed concerns the websites' lack of information on the PAO/PGI that protects the products. Only $55.17 \%$ of the websites display this information. Thus, despite the efforts the companies have made to obtain that certification, and their consumers' positive valuation of it, companies do not communicate that distinctive mark efficiently. (see Table 3 - Figure 1). 


\section{Table 2 - Development of website}

\begin{tabular}{|c|c|c|c|c|c|}
\hline \multirow[b]{2}{*}{ Development of website } & \multicolumn{3}{|c|}{ Frequency (\%) } & & \multirow[b]{2}{*}{$\begin{array}{l}\mathbf{5} \\
1.84\end{array}$} \\
\hline & $\begin{array}{l}\mathbf{1} \\
1.15\end{array}$ & $\begin{array}{l}\mathbf{2} \\
1.15\end{array}$ & $\begin{array}{c}\mathbf{3} \\
33.33\end{array}$ & $\begin{array}{c}\mathbf{4} \\
42.53\end{array}$ & \\
\hline Graphics & & & 2.30 & & \\
\hline Images & & & 98.85 & & \\
\hline Mobile elements & & & 59.77 & & \\
\hline Links & & & 31.03 & & \\
\hline Novelty or originality & & $\begin{array}{l}\mathbf{1 - 3} \\
4.60\end{array}$ & $\begin{array}{r}\mathbf{4 - 6} \\
29.89\end{array}$ & $\begin{array}{r}\mathbf{7 - 1 0} \\
65.52\end{array}$ & \\
\hline Information in other languages & & & 60.92 & & \\
\hline Usability & & $\begin{array}{l}\mathbf{1 - 3} \\
1.15\end{array}$ & $\begin{array}{c}\mathbf{4 - 6} \\
10.34\end{array}$ & $\begin{array}{r}\text { 7-10 } \\
88.34\end{array}$ & \\
\hline Site Map & & $\begin{array}{l}\mathbf{1 - 3} \\
1.15\end{array}$ & $\begin{array}{c}\mathbf{4 - 6} \\
12.64\end{array}$ & $\begin{array}{c}\text { 7-10 } \\
86.21\end{array}$ & \\
\hline Search Engine & & & 10.34 & & \\
\hline Glossary & & & 0.00 & & \\
\hline Date of last update & & & 3.45 & & \\
\hline
\end{tabular}

\section{Table $3 \cdot$ Figure 1. Information on company}

\begin{tabular}{|l|c|}
\hline & Frequency \\
\hline Name of company & 100.00 \\
\hline $\begin{array}{l}\text { Address and location } \\
\text { of winery/factory }\end{array}$ & 96.55 \\
\hline Indication PAO/PGl & 55.17 \\
\hline Company logo & 97.70 \\
\hline Product commerc. & 97.70 \\
\hline Brands commerc. & 91.95 \\
\hline Production commerc. & 8.05 \\
\hline
\end{tabular}

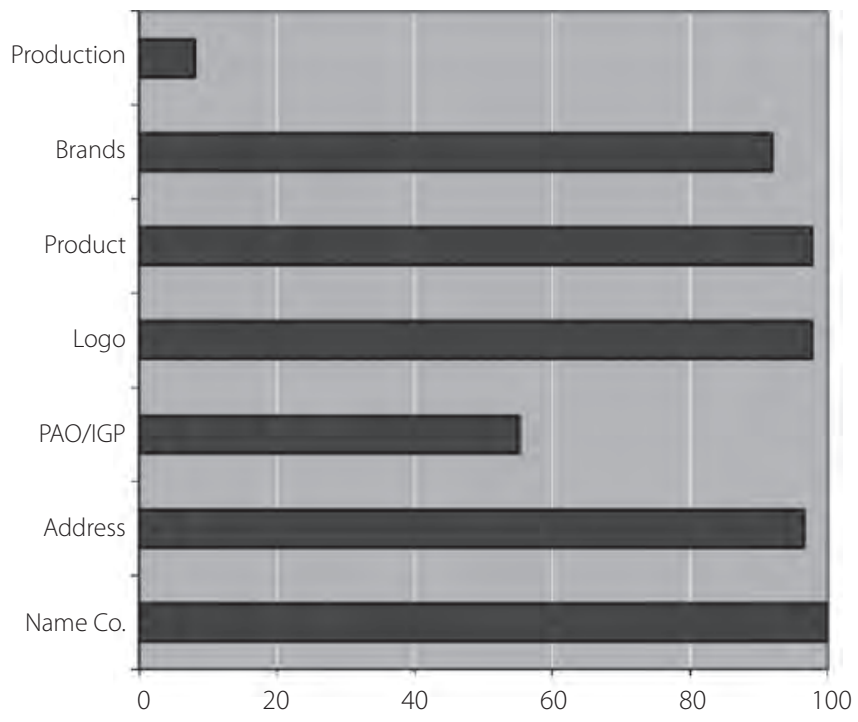


Companies show the main brands commercialised in $91.95 \%$ of the websites. This is essential because the consumers lack information and there is a large range of brands in the market. In this respect, such is the lack of information that consumers sometimes buy a brand without knowing that it is produced under an Appellation of Origin, or, even more damaging, do not buy a particular brand because they think that it is not covered by a quality label. At other times consumers mistake a particular brand for an Appellation of Origin. On the other hand, when a consumer fails to link a brand to a specific company, the company's prestige and experience become irrelevant in the purchase decision.

Only seven websites show the production sold. Such information would help increase or support the buyer's confidence in purchasing the company's products.

\section{Information on production process}

About $75 \%$ of the websites analysed provide information on the product types most sold by the company. More important is information about raw materials - one of the bases on which these products' differential quality is sustained. Thus, $74.71 \%$ of the websites report the raw materials used in making the products commercialised by the firms. Ideally, of course, this would be $100 \%$.

Another pillar on which quality certification is based is the production process, which should also be shown or indicated on company websites; this was present on a high percentage of the websites consulted (75.86\%). However, this emphasis drops when offering other highly useful information, such as the area the product is produced. This is a decisive fact for the buyer when choosing between different brands and/or PAOs or PGIs, as the conditions of the geographic area contribute to the quality of the product made there. Moreover, company websites should detail local weather conditions and the orography where products are made. These contribute to the quality of the raw materials, and hence are a potential factor for consumer confidence in the quality of products. Less than a quarter of the websites evaluated record that information.

Another key factor of consumer confidence concerns the quality control systems put in place by the company, which only $21.84 \%$ of the websites mention. Composition of the products is another decisive aspect, of major importance to the buyer. Only $66.67 \%$ of these companies' websites present this information. Approximately half the websites describe the technology used.

Finally, consumers value highly recommendations on how to consume the product. This improves the attractiveness of these websites and loyalty to them, creating a means of lasting contact with present and potential consumers. Such advice also increases situations in which consumption may take place -a highly important aim for such products. Despite all this, only $49.43 \%$ of the websites analysed feature such recommendations. (See Table 4 - Figure 2)

\section{Information on product}

On $97.70 \%$ of the websites, product catalogues or other presentation methods provide fundamental information on the offer. Furthermore, images, which boost product memory and recognition, appear on $93.10 \%$ of the websites. That percentage drops for product labels. Consumers value this feature, not only for the information it 


\section{Table 4 - Figuere $\mathbf{2}$ - Information on production process}

\begin{tabular}{|lc|}
\hline & Frequency \\
\hline Most commercialised product type & 75.86 \\
\hline Raw materials & 74.71 \\
\hline Production process & 75.86 \\
\hline Production area & 68.97 \\
\hline Technology used & 50.57 \\
\hline Composition & 66.67 \\
\hline Quality control systems & 21.84 \\
\hline Recommendations on how to & 49.43 \\
\hline consume product, recipes .... & 22.99 \\
\hline Weather information & 20.69 \\
\hline Description of orography & \\
\hline
\end{tabular}

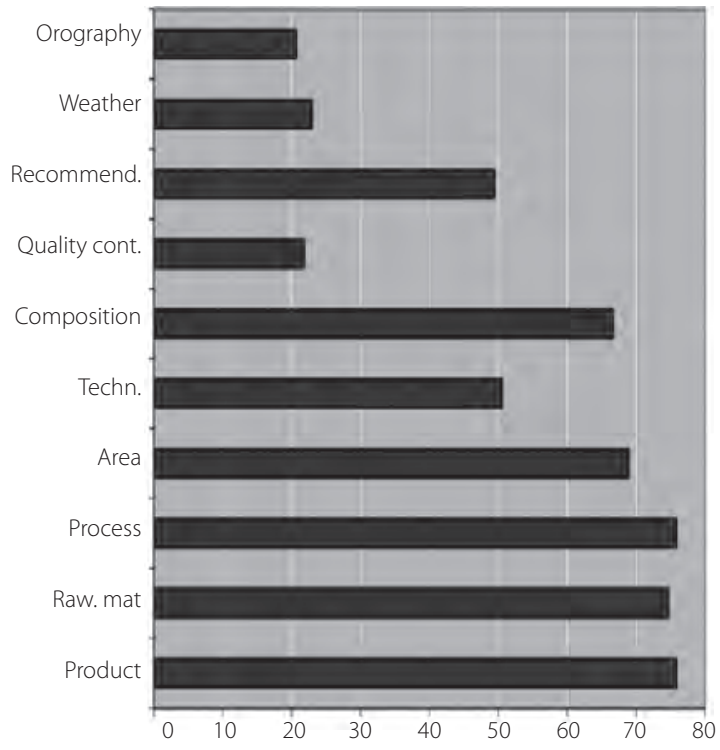

contains (which can in fact be provided in other areas of the website) but also for the image of the firm that it transmits.

\section{Information on sale}

The websites analysed do not usually display product price, since these websites are a medium of communication more than for making sales. Thus, only $12.64 \%$ of the websites provide this information, with $28.74 \%$ permitting online purchasing.

\section{Table $\mathbf{5} \cdot$ Information on product}

\begin{tabular}{|lc|}
\hline & Frequency \\
\hline Products or catalogue & 97.70 \\
\hline Image of product & 93.10 \\
\hline Label & 47.13 \\
\hline
\end{tabular}

Sales are also hindered by not clearly specifying the payment methods available, nor providing mechanisms to guarantee payment security. Thus, $13.79 \%$ of the websites do not provide information about payment methods. When the method is mentioned, the most common options are transfers, payment on delivery, and credit card. Only five of the websites analysed try to avoid the payment insecurity barrier to e-commerce by providing information about their security mechanisms.

Another obstacle to electronic sales lies in the lack of information on the terms of delivery and other services, only six of the websites consulted providing such information. Finally, the lack of purchasing suggestions concerning price, discounts or offers limits the potential of this channel as an immediate means of sale. Thus, just 


\section{Figure 4 • Table $6 \cdot$ Information on sale}

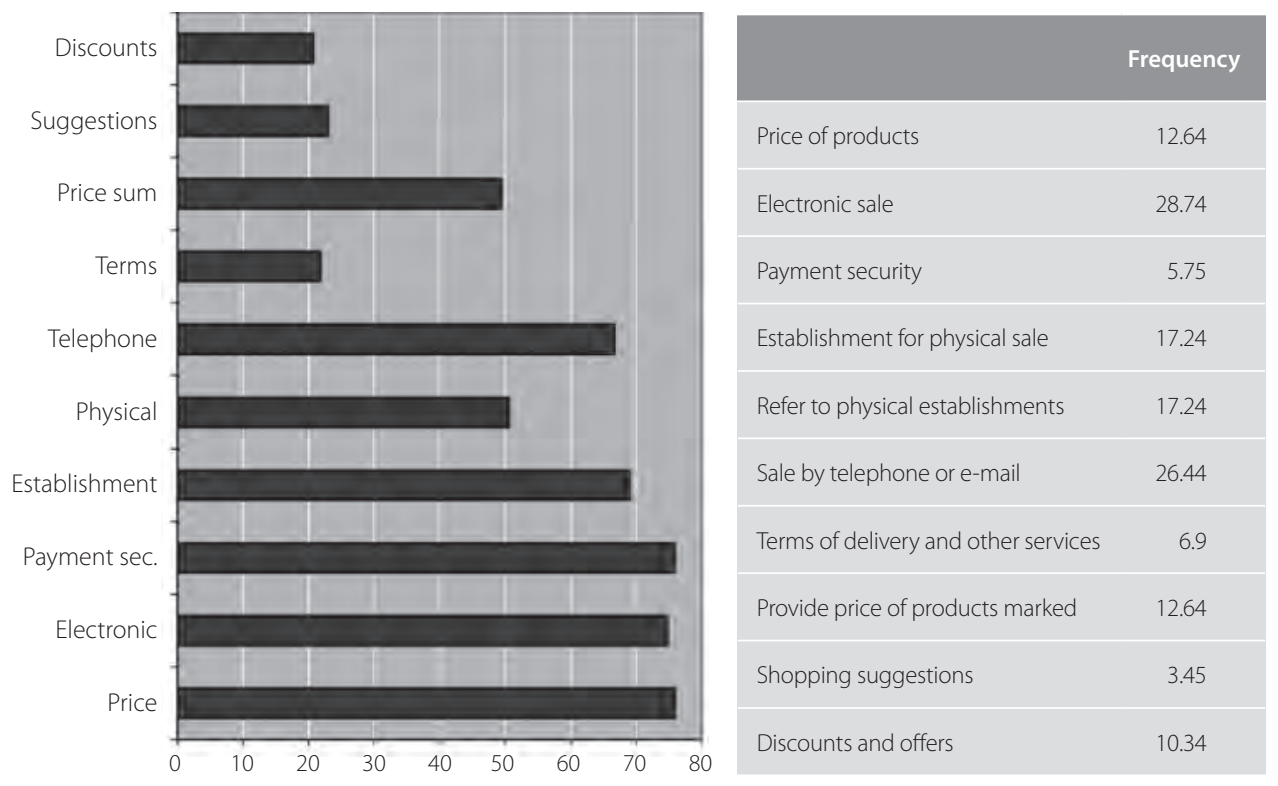

$10.34 \%$ of the websites have offers, and only three mention any shopping suggestions.

Just over a quarter of the websites consulted offer the option of purchasing by telephone or by e-mail. Firms possess an establishment for the physical sale of their products in $17.24 \%$ of cases, and the websites refer visitors to these stores.

\section{Communication}

Most of the websites consulted provide a brief reference to the history of the company (74.71\%) and contact details: post (95.40\%), e-mail (97.70\%) and telephone (96.55\%). Information on company export activity appears on $11.49 \%$ of the websites consulted. However, corporate awards and mentions only appear on $27.59 \%$.

Another corporate-image-enhancing feature is information on the organisation of visits and tastings, although despite these activities, the firms offer very little information about them either before, during or after such events. Nor do websites communicate firms' activities in the area of sponsorship and other public relations actions. Only one website uses product endorsers. This would undoubtedly contribute to improving the corporate image, as well as buyers' confidence in the product.

Other information is equally rare, although it would be very useful to attract attention to a particular page and hence attract potential buyers. Thus, presentation of or links to news in the world of wine, cheese, and so on, would contribute to positioning the website as an interesting communications medium for consumers, improving their receptiveness to the information appearing on it. Other options that would also 
help improve the image and strengthen buyer loyalty to this medium would be the possibility of joining clubs or forums, or the organisation of competitions, which are present in just four websites in the former case, and one in the latter.

In parallel to this, information on gastronomy and tourism would increase the attractiveness of these websites. Despite this, tourism information is available on only $18.39 \%$ of the websites, and gastronomic information on $10.34 \%$. A total of ten websites mention health-related aspects of consumption of these products. Finally, 20.69\% of the websites consulted have a press dossier, and only two offer to send consumers catalogues. (See Table 7.Figure 5)

\section{Conclusion}

The Internet provides a wide range of opportunities for small and medium-sized enterprises, although few SMEs use this medium to its optimum advantage. Of the 259 companies consulted in the agro-food sector in Castile and Leon that commercialise quality products, only $33 \%$ have active websites, and these vary in terms of their quality of content, development and functionality.

These sites are well or moderately well developed in most cases, although the type of information that each website offers varies considerably. The firms use their websites mainly to communicate with the consumer. The results indicate the general need for the firms to strengthen the interactivity of their websites, as well as to exploit their potential as a sales channel, improving the transactional levels and relationships with the consumer.

In general, the interfaces of the websites analysed obtain an adequate valuation, as does the usability of the siteMoreover, and as in the case

\section{Table $7 \cdot$ Communication}

\begin{tabular}{|c|c|}
\hline & Frequency \\
\hline History of company & 74.71 \\
\hline Post & 95.40 \\
\hline E-mail & 97.70 \\
\hline Telephone & 96.55 \\
\hline Information on exports & 11.49 \\
\hline Site visits to company & 8.05 \\
\hline Tasting wine and edible products & 5.75 \\
\hline Gastronomy & 10.34 \\
\hline Tourism & 18.39 \\
\hline Health & 11.49 \\
\hline World of wine/cheese... & 20.69 \\
\hline Club or forums & 4.60 \\
\hline Competitions & 1.15 \\
\hline Catalogues & 2.30 \\
\hline Press dossier & 20.69 \\
\hline Annual accounts & 0.00 \\
\hline Other company actions & 13.79 \\
\hline Endorsements & 1.15 \\
\hline Awards and mentions & 27.59 \\
\hline
\end{tabular}

of other consumer touch points, websites transmit a corporate image, so information such as awards or mentions obtained, organisation of visits, tasting of wines or edible products, as well as other actions such as sponsorship and communication concerning endorsements, would help maintain or improve the position and image of the company. 


\section{Figure $5 \cdot$ Communication}

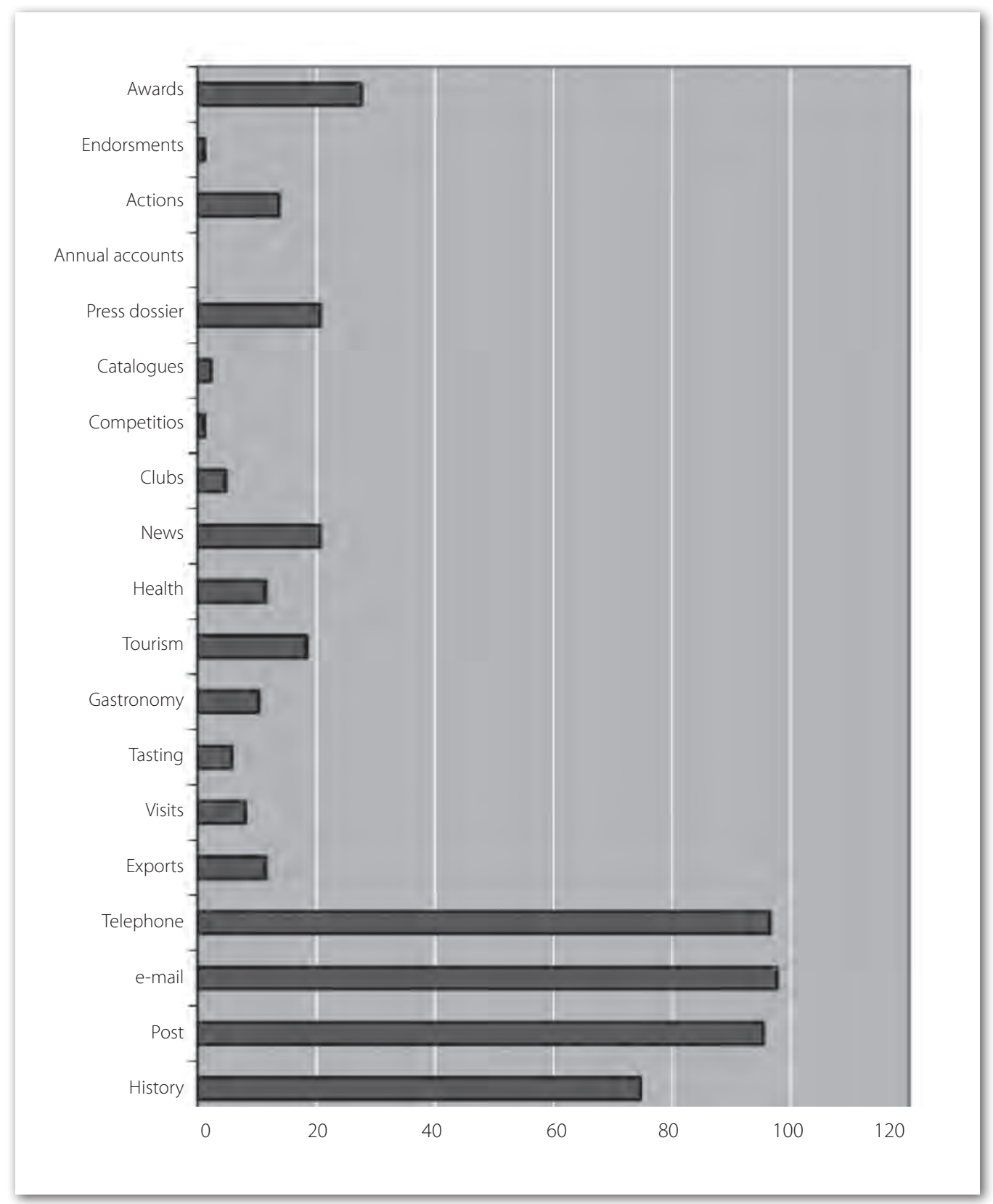

In parallel, the content and actual develop- long-term relationship with present and potenment of the website must aim to consolidate it as tial purchasers. Thus, companies should set up a lasting means of communication, generating a clubs or discussion groups, and offer news about 
quality agro-food products. This would help keep customers coming back to their websites.

Finally, the firms have made little effort at selling over the internet, this being mainly due to logistic problems. Firms should aim their efforts at establishing this as a complementary channel, not as a substitute to selling via their own establishments or specialised stores.

As future lines of research, the authors are expanding their analysis of the websites of agro-food SMEs to other regions of Spain, in order to gain a global perspective on Internet use among these firms, as well as to identify any inter-regional differences. After this analysis, the aim will be to compare the positioning of Spanish agro-food SMEs with those from other countries in relation to whether they use the Internet in their marketing strategies or not, as well as how much they use the medium. 


\section{References}

Aguiló, I.F. (1996). "Hay que estar en internet ya", Revista de Estudios Empresariales, No. 92, pp. 36-44.

Bonsón, E. and Sierra, G.J. (1997). Internet empresarial, RaMa, Madrid.

Carpintier, R. (1996). Internet hoy. Cómo hacer negocios en la red, Ra-Ma, Madrid.

Ditto, S. and Pille, B. (1998). "Marketing on the Internet", Healthcare Executive, Vol. 13, No.5, pp. 54-55.

Gómez-Limón, J.A. (2002). "El uso de internet en el comercio y marketing del vino", in García, J.I. (Ed.). Comercialización y marketing del vino, Publicaciones INEA, Valladolid, pp. 149-170.

Hamill, J. (1997). "The Internet and international marketing", International Marketing Review, Vol. 14, No.5, pp. 300-323

Kleindl, B. (2000). "Competitive dynamics and new business models for SMEs in the virtual market", Journal of Developmental Enterpreneurship, Vol.5, No.1, pp. 73-85.

Kula, V. and Tatoglu, E. (2003). "An exploratory study of Internet adoption by SMEs in an emerging market economy", European Business Review, Vol. 15, No. 5, pp. 324333.

World Trade Organization (1998). Electronic trade and the role of the WTO, WTO, Geneva.

Quelch, J.A. and Klein, L.R. (1996). "Internet and international marketing". Harvard-Deusto Business Review, No. 75, pp. 95-103.

Sánchez, I., García, F. and Larrumbide, C. (1997). "Las nuevas tecnologías aplicadas al marketing", Dirección y Progreso, No. 154, pp. 5-13.
Sparkes, A. and Thomas, B. (2001). "The use of the Internet as a critical success factor for the marketing of Welsh agri-food SMEs in the twenty-first century", British Food Journal, Vol. 103, No.5, pp. 331-347.

Stevenson, A. and Hamill, Jim (2002). "Internet forum", International Marketing Review, Vol. 19, No. 3, pp. 323-326.

Geiger, S. and Martin, S. (1999). "The Internet as a relationship marketing tool - some evidence from Irish companies", Irish Marketing Review, Vol. 12, No. 2, pp. 24-36.

Lee, C-S. (2001). "An analytical framework for evaluating e-business models and strategies", Internet Research, Vol. 11, No. 4 , pp. 349-360.

Daniel, E., Wilson, H. and Myers, A. (2002). "Adoption of e-commerce by SMEs in the UK", International Small Business Journal, Vol. 20, No. 3, pp. 253-268.

Siu, W-S. (2002). "Marketing activities and performance: a comparison of the Internet-based and traditional small firms in Taiwan", Industrial Marketing Management, Vol. 31, No. 2, pp. 177-188.

Pratt, J.H. (2002). E-Biz: Strategies for small business success, U.S. SBA Office of Advocacy, available at: http://www.sba.gov/ advo/research/rs220tot.pdf

Auger, P., Barnir, A. and Gallaugher, J.M. (2003). "Strategic orientation, competition, and Internet-based electronic commerce", Information Technology and Management, Vol. 4, No. 2-3, pp. 139-164.

INE (2007). Survey on the use of ICT and Electronic Commerce (EC) by companies 2005-2006, Data base INEbase, Spanish Statistical Institute, Spain, available at: http://wwwine.es/inebase. 